\title{
The effect of neighbouring klipspringer on the scent-marking behaviour of a group of klipspringer in the Kruger National Park
}

\author{
M. Kruger, J. du P. Bothma and J.M. Kruger
}

M. Kruger, J. du P. Bothma and J.M. Kruger. 2002. The effect of neighbouring klipspringer on the scent-marking behaviour of a group of klipspringer in the Kruger National Park. Koedoe 45(1): 87-92. Pretoria. ISSN 0075-6458.

Both the male and the female klipspringer scent-mark their ranges. A pair of pre-orbital glands below the eyes produces the scent. The secretion is a sticky, substance that is deposited on a suitable twig. Klipspringer scent marks were surveyed in a specific klipspringer range in the Kruger National Park with the use of a strip transect method. The results showed that klipspringer in the Kruger National Park scent-mark more frequently on the boundaries of their ranges and also more on those sides where there is another resident klipspringer group.

Key-words: Klipspringer, scent-marking, behaviour, range, neighbours.

M. Kruger, J. du P. Bothma, Centre for Wildlife Management, University of Pretoria, Pretoria 0002 South Africa; J.M. Kruger, Conservation Services: South African National Parks, Kruger National Park, Private Bag X402, Skukuza, 1350 South Africa. (M. Kruger, Current address: Conservation Services, South African National Parks, Private Bag X402, Skukuza, 1350 South Africa.)

\section{Introduction}

Scent-marking behaviour has long been regarded as an important component of animal communication (Thiessen \& Rice 1976). A number of hypotheses to explain why animals scent-mark have been put forward. These range from deterrence of intruders (Hediger 1949) to the establishment of a familiar smell within the range (Johnson 1973). One such hypothesis proposes that the scent advertises the identity of a range inhabitant to an intruder, enabling the latter to assess the holder's status, thus avoiding costly fights (Gosling 1982). Scent-marking is also considered to be associated with dominance in many animal species (Ralls 1971; Stoddard 1976; Brown \& McDonald 1985; Kappeler 1980; Somers et al. 1990).

Like other small antelope (Cohen \& Gerneke 1976) both the male and female klipspringer scent-mark their ranges. This chemical communication functions as an unmistakable cue to ownership of a specific range. The scent is produced as a secretion by a pair of pre- orbital glands just below the eyes. The animal positions its head at a certain angle and rubs it against a suitable twig that normally points in an upward direction so that the twig is inserted directly into the gland. A milky substance is secreted that has a sweet, aniseed-like scent which turns brown once dried.

The hypothesis for this preliminary study of scent-marking in the klipspringer in one study area in the Kruger National Park was that klipspringer would mark more frequently towards the boundaries of their territories, and also more frequently on those sides where there were resident neighbouring klipspringer in their proximity.

\section{Study Area}

The Kruger National Park is situated in the Lowveld of the Mpumalanga and Northern Provinces along the northeastern boundary of the Republic of South Africa. This park lies between $22^{\circ} 19^{\prime}-25^{\circ} 32^{\prime}$ S latitude and $30^{\circ} 54^{\prime}$ 
$-32^{\circ} 02^{\prime} \mathrm{E}$ longitude. This study was conducted in the Nwatindlopfu Spruit area, approximately $25 \mathrm{~km}$ north-east of Skukuza in the Central District of the Kruger National Park. This area was selected because it had more than 10 known resident groups of klipspringer in close proximity. This area can briefly be described as follows. According to the landscape classification of the Kruger National Park by Gertenbach (1983), this area includes two landscapes. They are the thickets of the Sabie and Crocodile rivers and the mixed Combretum species / Terminalia sericea woodland. The area is underlain by granite and gneiss, with numerous dolerite intrusions that are more than $10 \mathrm{~m}$ wide (Schutte 1986). The altitude of the landscape varies from $200 \mathrm{~m}$ to $500 \mathrm{~m}$ above sea level with gently sloping hills and valleys.

\section{Vegetation}

The vegetation of this area can be described as mixed Combretum savanna woodland with dense thorn bush thickets on the banks of the spruits and rivers (Pienaar 1963). The dominant woody species are Acacia nigrescens, Combretum apiculatum, Grewia bicolor, Grewia flavescens, Sclerocarya birrea, Euclea divinorum, Spirostachys africana, Dichrostachys cinerea, Ziziphus mucronata, Lonchocarpus capassa, Strychnos madagascariensis, Cissus cornefolia, Ormocarpum trichocarpum and Dalbergia melanoxylon. The herbaceous grass layer in the area is dominated by Pogonarthria squarrosa, Perotis patens, Melinis repens, Digitaria eriantha, Panicum maximum, Aristida congesta, Schmidtia pappophoroides, Urochloa mosambicensis, Heteropogon contortus, Enneapogon cenchroides, Bothriochloa radicans and Themeda triandra. The dominant forbs are Waltheria indica, Evolvulus alsinoides, Heliotropium steudneri, Dyschoriste rogersii, Abutilon astro-africanum, Justicia flava, Sansevieria hyacinthoides, Rhynchosia totta, Cassia mimosoides, Commelina bengalensis and Hibiscus micranthus.

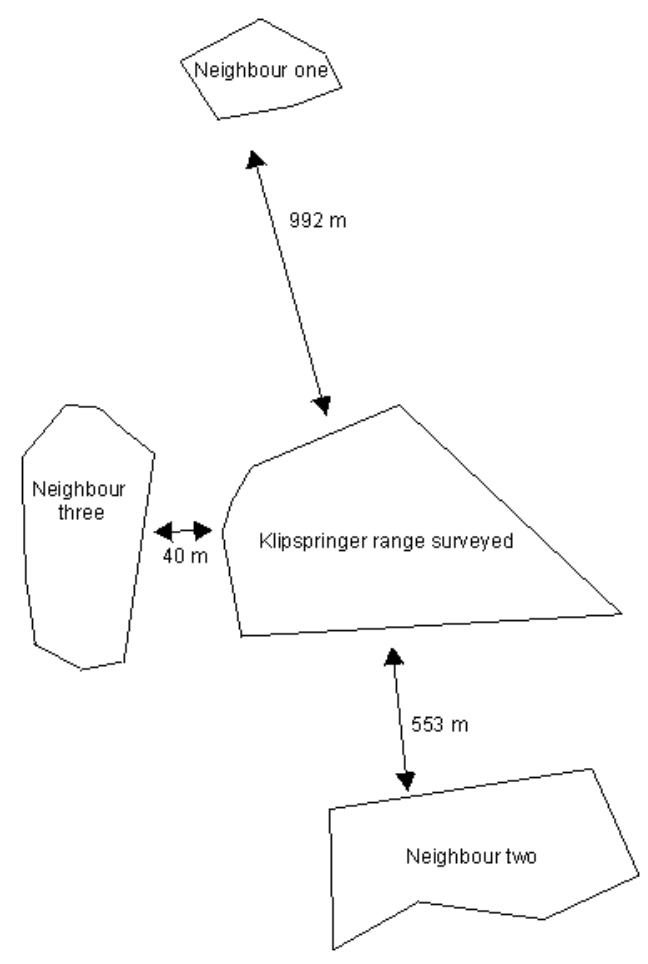

Fig. 1. Schematic presentation of a klipspringer range that was surveyed for scent marks, and the proximity of the nearest neighbours.

\section{Mammals}

The largest population of impala Aepyceros melampus in the Kruger National Park most probably occurs in this area. Other mammals include the kudu Tragelaphus strepsiceros, common duiker Sylvicapra grimmia, steenbok Raphicerus campestris, bushbuck Tragelaphus scriptus, giraffe Girraffa camelopardalis, sable antelope Hippotragus niger, warthog Phacochoerus aethiopicus, elephant Loxodonta africana, white rhinoceros Ceratotherium simum and black rhinoceros Diceros bicornis. The predators that occur in the area are the lion Panthera leo, leopard Panthera pardus, cheetah Acinonyx jubatus, wild dog Lycaon pictus and spotted hyaena Crocuta crocuta. 


\section{Materials and methods}

Klipspringer scent marks were surveyed with the use of a strip transect method. The transects were placed out from the centre of the range of a specific klipspringer group in the Nwatindlopfu Spruit area in the four directions, viz., north, south, east and west. Each transect was $100 \mathrm{~m}$ wide and the survey was done from the centre to somewhat beyond the known boundary of the range of that group. Each plant in the transect was inspected carefully for scent marks. When scent marks were found, the type of plant, the position of it in the transect and the number of marks present were recorded. The distance between this scent mark and the known territory boundary of the nearest klipspringer group was also recorded. Figure 1 shows the schematic range of klipspringer surveyed, and its position relative to the closest neighbours. The distances between the klipspringer range and the neighbours were obtained by calculating the distance between the known territory boundaries of the studied klipspringer group and the observed klipspringer surrounding them.

\section{Data analysis}

A two-fold approach was used to analyse the scentmarking data. The first approach was to investigate the spatial distribution of these marks so as to determine whether they were distributed at random or were clumped within the transects. The null hypothesis that was tested was that a klipspringer scentmarks randomly throughout its range. Should this be true, then the next approach was to use log-linear regression techniques in an effort to explain the pattern found.

Since the variable that was tested was the number of scent marks, normal linear regression methods of analysis were, however, not suitable because this linear method may lead to negative counts, and the variance will not be constant (Crawley 1996). Loglinear regression techniques or the Poisson distribution were therefore used to analyse the data. The Poisson distribution is used in cases where it is known how many times an event happened but where it is not known how many times an event did not happen. Here it meant how many times a klipspringer scent-marked within its range (Crawley 1996).

\section{Variables recorded}

The following variables were recorded:

- the number of scent marks. These were counted in four directions from the centre of the range as described above;
- the distance between a scent mark and the nearest neighbouring klipspringer;

- the distance from the centre of the range to the nearest neighbouring klipspringer;

- the number of neighbouring klipspringer bordering the range in all directions.

\section{Factors affecting scent-marking: model fitting}

The full model that was fitted included the variables indicated above. The only interaction term that was included in the model was the interaction between the variable distance between the scent marks and the neighbouring klipspringer and the variable number of neighbouring klipspringer. When the full model was fitted it was determined that the data were over dispersed which means that the probability that we were attempting to model was not constant within each cell, but behaved like a random variable. To correct for this we assumed that the variance was proportional to the binomial variance and not equal to it. We calculated the ratio of scaled deviance to degrees of freedom and used the scale directive to alter the scaled deviance (Crawley 1996). In order to evaluate the extent to which an adopted model fits a set of data the distribution of deviance is needed. The deviance is asymptotically distributed as $\chi^{2}$ with $(n-p)$ degrees of freedom, where $n$ is the number of observations and $p$ is the number of unknown parameters included in the model. In order to obtain the best model the constant was first fitted and then each variable was included in the model one at a time. A variable was considered significant when the change in deviance associated with including that variable exceeded the chisquare critical value at $P<0.05$ for the number of degrees of freedom that the variable conferred (Crawley 1996).

\section{Results}

\section{Spatial distribution}

Figure 2 shows the distribution of the scent marks as a three-dimensional map in which the third vertical dimension reflects the value of the quantitative data. The latter dimension represents the density of the scent marks. It is clear that the scent marks appear to be clumped in specific areas, mainly along the border of the range, with hardly 


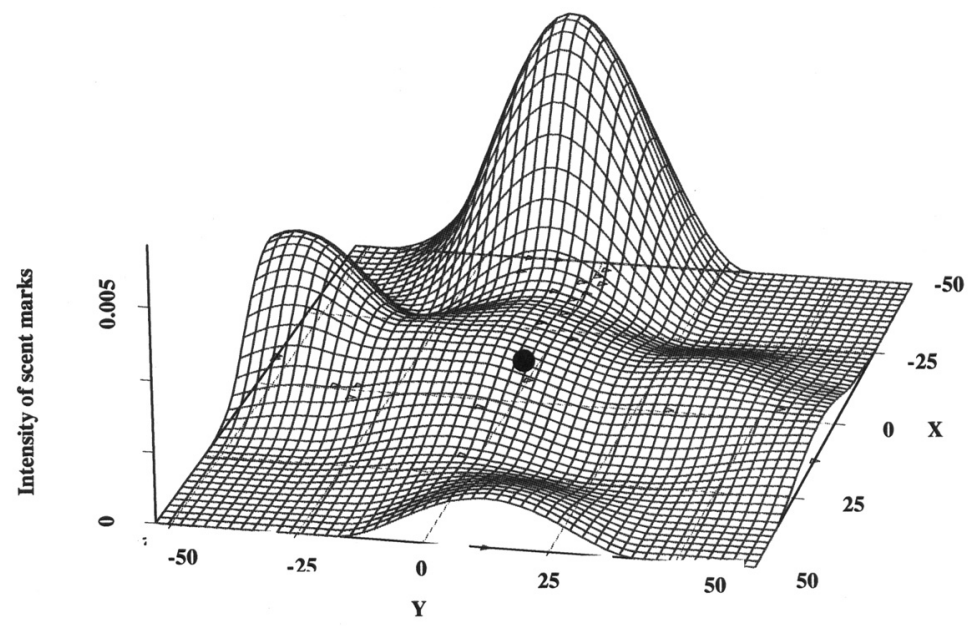

Figure 2. Three-dimensional representation of klipspringer scent marks in the Kruger National Park to show the distribution of scent marks. The black dot shows the centre of the range.

any scent-marking occurring in the centre of the range. When this representative pattern was subjected to a nearest neighbour analysis (Krebbs 1989), and was compared with an expected random distribution, the index of aggregation $(\mathrm{R})$ was 0.36128 . This ratio indicates a deviation of the observed pattern from an expected random pattern. When the spatial pattern is random, then $\mathrm{R}=1$, and when clumping occurs then $\mathrm{R}$ approaches zero. Therefore it can be concluded that the scent marks where indeed clumped in specific areas. To test the significance of the devi- ation from a random pattern, the $Z$ statistic was calculated, where $\mathrm{Z}=\mathrm{RA}-\mathrm{RE} / \mathrm{SE}, \mathrm{RA}=$ the mean distance to the nearest neighbour, $\mathrm{RE}=$ the expected distance to the nearest neighbour, and $\mathrm{SE}=$ the standard error of the expected distance to nearest neighbour. This test yielded a $\mathrm{Z}$ value of 20.79144 , which is greater than $1.96(P=0.05)$. Meaning the null hypothesis that the scent marks are randomly spaced is rejected (Krebs 1989), therefore, they show a clumped pattern.

Table 1

Poisson regression analyses of the effect of neighbouring klipspringer and the distance of scent marks from the centre of the range on the number of scent marks in klipspringer in the Kruger National Park. Star notation in the table represents the interaction between 2 variables

\begin{tabular}{lccc}
\hline Variable & $\begin{array}{c}\text { Degrees } \\
\text { of freedom }\end{array}$ & $\begin{array}{c}\text { Change } \\
\text { in deviance }\end{array}$ & $\begin{array}{c}\text { Probability } \\
\text { value }\end{array}$ \\
\hline $\begin{array}{l}\text { Number of neighbouring klipspringer } \\
\begin{array}{l}\text { Distance from centre of range to nearest } \\
\text { neighbouring klipspringer }\end{array}\end{array}$ & 1 & -4.511 & 0.0337 \\
$\begin{array}{l}\text { Distance between a scent mark and } \\
\text { nearest the neighbouring klipspringer }\end{array}$ & 1 & -8.884 & 0.0029 \\
$\begin{array}{l}\text { Distance between a scent -mark and } \\
\text { the nearest neighbour. }\end{array}$ & & -7.854 & 0.0050 \\
$*$ Number of neighbours & 1 & & \\
\hline
\end{tabular}




\section{Log-linear regression}

The variable that had the most influence on the number of scent marks was the distance to the nearest neighbouring klipspringer, because it resulted in the greatest change in deviance when it was excluded from the model - and the probability value associated with it was the smallest. The variable of the number of neighbouring klipspringer had the least effect on the number of scent marks because the drop in deviance was the smallest and the probability associated with it was the largest of the significant variables. The interaction between the distance between a scent mark and the nearest neighbouring klipspringer, and between the number of neighbouring klipspringer was, however, not significant $(P>0.05)$ (Table 1).

The change in deviance and the corresponding degrees of freedom for each of the variables tested are shown in Table 1. The effect of distance to the nearest neighbouring klipspringer and the distance to a given scent mark are illustrated in Figs. $3 \& 4$.

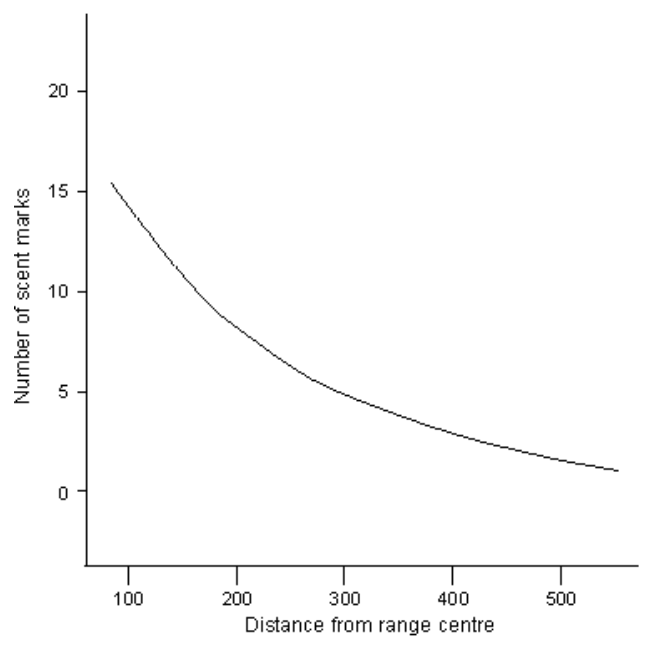

Fig. 3. The effect of the distances (m) from the scent mark to the nearest neighbouring klipspringer on the number of scent marks produced by the klipspringer group studied in the Kruger National Park as obtained from log-linear regression techniques.

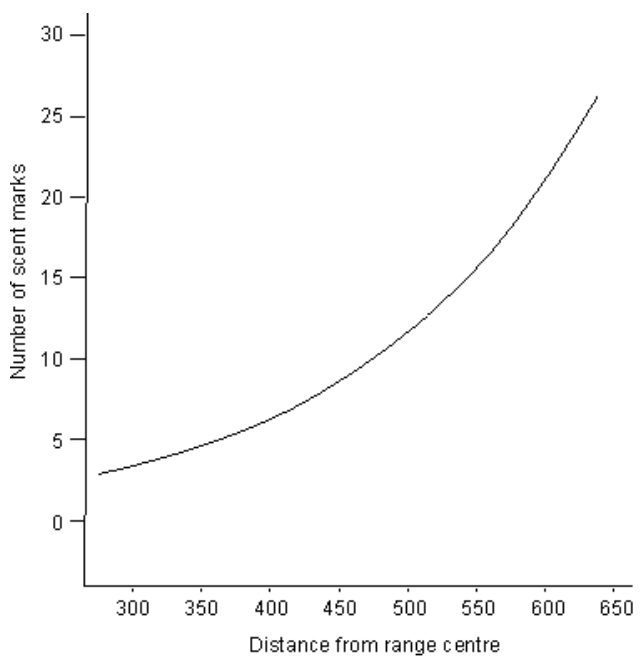

Figure 4 The effect of the distance from the centre of the studied klipspringer range on the number of scent marks produced by these klipspringer in the Kruger National Park.

\section{Discussion}

It is clear that as the distance between the scent marks and the nearest neighbouring klipspringer increases, the number of scent marks decreases (Fig. 3). Therefore the closer a klipspringer is to a neighbouring klipspringer the more scent-marks will occur. Also, the further away that the scent marks are from the centre of the range, the more scent marks there are (Fig. 4). Therefore, the number of scent-marking increases near the boundaries of a range. It is also clear that the number of neighbours that a klipspringer have will affect the number of scent-marking (Table 1). However, the data are not conclusive because there were limited klipspringer concentrations. Nevertheless, the data does indicate that all the variables except the interaction between the distance between a scent mark and the nearest neighbouring klipspringer and the number of neighbouring klipspringer have a significant effect on the number of scent-marks in klipspringer in the Kruger National Park. 


\section{Conclusions}

Roberts (1998) observed a similar scentmarking pattern in klipspringer in the Limpopo River Valley of Zimbabwe as was found here with the use of a nearest-neighbour mapping technique. In the study by Roberts (1998) the scent marks were placed in a rough ring just within the range boundaries of a resident group. The result of the current preliminary study on scent-marking in the klipspringer in the Kruger National Park, supports the hypothesis that klipspringer will scent-mark more frequently on the boundaries of their ranges, and also more on those sides of the range where there is another resident klipspringer group. We therefore conclude that scent-marking in klipspringer is used as a spacing behaviour.

\section{Acknowledgements}

We would like to thank the South African National Parks, Kodak SA and the CSIR for their financial assistance.

\section{References}

Brown, R.E \& D.W. Macdonald. 1985. Social odours in mammals. Oxford: Clarendon Press.
Cohen, M. \& W.H. Gerneke. 1976. Preliminary report on the inter-mandibular cutaneous area and the infra-orbital gland of the Steenbok. Journal of South African Veterinary Association 47(1):35-37.

Crawley, M.J. 1996. Glim for ecologists. Cambridge: University Press.

Gertenbach, W.P.D. 1983. Landscapes of the Kruger National Park. Koedoe 26 :9-121.

GosLING, L.M. 1982. A reassessment of the function of scentmarking in territories. Zeitschrift für Tierpsychologie 60: 89-118.

Hediger, H. 1949. Säugetier-Territorien und ihre Makierung. Bijdragen tot de Dierkunde 28: 172-184

JOHNSON, R.P. 1973. Scent marking in mammals. Animal Behaviour 21: 521-535

KAPPELER, P.M. 1990. Social status and scent marking behaviour in Lemur catta. Animal Behaviour 40: 774-788.

KrebBS, J.C. 1989. Ecological methodology. New York: Harper Collins.

PIENAAR, U. DE V. 1963. The large mammals of the Kruger National Park - their distribution and present-day status. Koedoe 6:1-37.

RALLS, K. 1971. Mammalian scent marking. Science 171: 443-449

SCHUTTE, I.C.1986. The general geology of the Kruger National Park. Koedoe 29 : 13-37.

SOMERS, M., O.A.E. RASA \& P.J. APPS. 1990. Marking behaviour and dominance in suni antelope (Neotragus moschatus). Zeitschrift für Säugetierkunde 55: 340-352.

STODDART, D.M. 1976. Mammalian odours and pheromones. London: Edward Arnold.

Thiessen, D. \& M. Rice. 1976. Mammalian scent gland marking and social behaviour. Psychological Bulletin 83: 505-539. 